\title{
Vegetation context influences the strength and targets of pollinator-mediated selection in a deceptive orchid
}

\author{
Nina Sletvold, ${ }^{1,3}$ John Magne Grindeland, ${ }^{2}$ and Jon Ågren ${ }^{1}$ \\ ${ }^{1}$ Department of Plant Ecology and Evolution, Evolutionary Biology Centre, Uppsala University, Norbyvägen 18 D, \\ SE-752 36 Uppsala, Sweden \\ ${ }^{2}$ Sør-Trøndelag University College, $N$-7004 Trondheim, Norway
}

\begin{abstract}
Clarifying the relationship between environmental context and the adaptive significance of floral traits is fundamental for an understanding of spatial and temporal variation in pollinator-mediated selection. We manipulated vegetation height and pollination regime of the orchid Dactylorhiza lapponica in a factorial design to test whether pollinatormediated selection on floral traits is stronger in tall than in short vegetation, and whether this difference is larger for visual traits affecting pollinator attraction than for traits affecting pollination efficiency. In tall vegetation, pollinators mediated strong selection for taller plants (change in selection gradient for pollination, $\left.\Delta \beta_{\text {poll }}=0.33\right)$, more flowers $\left(\Delta \beta_{\text {poll }}=0.34\right.$ ), and longer spurs $\left(\Delta \beta_{\text {poll }}=0.42\right)$. In short vegetation, there was no significant selection on plant height, and pollinator-mediated selection on number of flowers and spur length was reduced by $52 \%$ and $25 \%$, respectively. The results demonstrate experimentally that vegetation context can markedly influence the strength of pollinator-mediated selection on visual display traits, and indicate that this effect is weaker for traits affecting pollination efficiency. The study illustrates how crossed manipulations of environmental factors can reveal the causal links between ecological context and selection on floral traits.
\end{abstract}

Key words: adaptive significance; context-dependent selection; Dactylorhiza lapponica; ecological context; floral evolution; mechanism of selection; natural selection; plant-animal interactions; pollination efficiency; pollinator attraction.

\section{INTRODUCTION}

Determining the mode and strength of phenotypic selection in natural populations has been the subject of sustained interest since the publication of Lande and Arnold (1983), and several reviews synthesizing available data have emerged in recent years (Kingsolver et al. 2001, 2012, Harder and Johnson 2009, Siepielski et al. 2009). A recurring conclusion has been that, despite a large number of selection estimates, we still know surprisingly little about the ecological causes of selection (MacColl 2011, Kingsolver et al. 2012). Studies that manipulate environmental factors to reveal the agents of selection are still rare, and the identification of major selective agents and their variation across environmental gradients will be fundamental to advance our understanding of selection in the wild (MacColl 2011).

Biotic interactions often constitute important elements of the selection regime, and the pollination environment is one biotic factor that has been subject to manipulations in several studies of phenotypic selection in natural plant populations (Galen 1996, Fishman and Willis 2008, Sandring and Ågren 2009, Caruso et al. 2010, Parachnowitsch and Kessler 2010,

Manuscript received 23 October 2012; revised 4 February 2013; accepted 12 February 2013. Corresponding Editor: R. E. Irwin.

${ }^{3}$ E-mail: nina.sletvold@ebc.uu.se
Sletvold and Ågren 2010, Sletvold et al. 2010a, 2012, Bartowska and Johnston 2012). Pollinators have been experimentally identified as agents of selection both on traits likely to be involved in pollinator attraction and on traits affecting pollination efficiency, but the proportion of selection that can be attributed to pollinators varies among traits (Sletvold et al. 2010a, 2012). There may also be considerable spatiotemporal variation in the strength of pollinator-mediated selection on a given trait (Sletvold and Ågren 2010), suggesting that manipulations of both the pollination environment and other putative selective factors are required to understand variation in selection on floral traits.

The impact of environmental context on selection on floral traits may differ between traits affecting pollinator attraction and traits affecting pollination efficiency. Visual display traits such as inflorescence height, number of flowers and flower size are expected to influence plant attractiveness to pollinators, and the importance of such traits should depend on the density and height of the surrounding vegetation. Because the effect of floral display on pollination success should be stronger, pollinator-mediated selection on visual display can be expected to be stronger in tall vegetation than in short vegetation (Ehrlén et al. 2002, Ågren et al. 2006). In contrast, the adaptive significance of floral traits influencing the efficiency of pollination should not be related directly to variation in vegetation context, unless 
differences in vegetation are associated with differences in the morphology or flower-handling behavior of pollinators. However, the strength of selection is a result of both the correlation between trait and fitness and the variance in relative fitness, i.e., the opportunity for selection (Endler 1986). Pollinator visitation rate to short herbs can be expected to be higher in short compared to tall vegetation. This is likely to result in reduced pollen limitation and lower variation in relative fitness, and therefore also in weaker pollinator-mediated selection in general.

Some studies indicate that vegetation context influences selection on visual display. For example, the strength of pollinator-mediated selection on inflorescence height in the deceptive orchid Cypripedium acaule varied among microhabitats that differed in surrounding vegetation (O'Connell and Johnston 1998), and amongpopulation variation in seed predator-mediated selection on floral display in the perennial herb Primula veris was related to variation in canopy cover (Leimu et al. 2002, Kolb and Ehrlén 2010). However, vegetation context must be manipulated to be unambiguously linked to variation in selection (cf. Wade and Kalisz 1990), and to quantify how selection mediated by a specific agent depends on vegetation context, crossed manipulations are necessary (e.g., Ågren et al. 2006).

The deceptive bumble bee-pollinated orchid Dactylorhiza lapponica experiences pollinator-mediated selection on traits expected to affect pollinator attraction (plant height and number of flowers) and pollination efficiency (spur length; Sletvold et al. 2010a), and manipulations of number of flowers and spur length have demonstrated that both traits are direct targets of selection (Sletvold and Agren 2011a). In this study, we manipulated vegetation height and pollination regime in a factorial design, to test the following hypotheses: reduced vegetation height decreases (1) pollen limitation and (2) the strength of pollinator-mediated selection and (3) the decrease in strength of pollinator-mediated selection is larger for traits influencing pollinator attraction (plant height and number of flowers) than for traits influencing pollination efficiency (spur length).

\section{Material and Methods}

\section{Study species and site}

Dactylorhiza lapponica (Laest. ex Hartm.) Soó (Orchidaceae) is a long-lived, non-clonal terrestrial orchid, occurring in Fennoscandia, Scotland, and alpine areas in Central Europe. In Fennoscandia, D. lapponica is restricted to open lawn communities in calcareous fens and springs in the boreal vegetation zone. Plants emerge in late May-early June, and flowering individuals produce a single $7-30 \mathrm{~cm}$ tall inflorescence with $\sim 2-25$ cerise, short-spurred flowers without nectar production. The pollination system is generalized food deception, and pollen transfer efficiency in the study population has been estimated to 12\% (Sletvold and Agren 2011a). Flowers open from the base of the inflorescence and upward. Dactylorhiza lapponica is self-compatible, but depends on pollinators for successful fruit set (N. Sletvold, unpublished data). Low levels of fruit set are common (20-30\%; Sletvold et al. 2010b).

The present study was conducted in a population of approximately 800 flowering individuals located at Tågdalen, $\sim 450 \mathrm{~m}$ above sea level in central Norway $\left(63^{\circ} 03^{\prime} \mathrm{N}, 9^{\circ} 05^{\prime} \mathrm{E}\right.$; see Sletvold et al. [2010a, b] for a more detailed description of the study site). The population flowers during three to four weeks from mid to late June. At the site, the maximum height of the vegetation increases from $\sim 15-30 \mathrm{~cm}$ during the $D$. lapponica flowering period but, throughout the flowering period, there is considerable spatial variation both in vegetation height and density. The vegetation height in the immediate vicinity of $D$. lapponica individuals (within $15 \mathrm{~cm}$ ) ranges from less than $2 \mathrm{~cm}$ to the maximum recorded at the site throughout the flowering season. The study population is pollinated by worker bees of the species Bombus pascuorum and B. lucorum, and fruit production and fruit mass are strongly pollen limited (Sletvold et al. 2010a).

\section{Field experiment}

To examine the effects of vegetation height on pollinator-mediated selection, we manipulated vegetation height and pollination regime in a factorial design (tall vs. short vegetation, open-pollinated control vs. supplemental hand pollination, respectively).

In late June 2012, a total of 480 plants with flower buds were haphazardly chosen and individually tagged. We randomly assigned 120 plants to each of the four treatment combinations in the factorial experiment. For each plant, we recorded start of flowering (reported as day of year) and plant height to the nearest millimeter (distance from the ground to the topmost flower) on the day the first flower opened. On one of the two lowermost flowers on each individual, we measured spur length (distance from corolla to spur tip) and maximum corolla width and height to the nearest $0.1 \mathrm{~mm}$ with digital callipers. Corolla size was quantified as the product of width and height. We noted the total number of flowers at the end of the flowering period. In the shortvegetation treatment, we cut all the vegetation within $15 \mathrm{~cm}$ of the focal plant to about $2 \mathrm{~cm}$ above the ground (see Plate 1). The cutting treatment was repeated weekly during the flowering period. In the hand-pollination treatment, all flowers were cross-pollinated by rubbing one or two pollinia across each stigma, saturating the surface with pollen. We collected pollinia from within the group of plants receiving supplemental hand pollination, but also from plants not included in the experiment. During its flowering period, a handpollinated plant received pollen from multiple donors. At fruit maturation, we recorded the number of mature fruits produced and harvested up to three mature fruits spread across the inflorescence to determine mean fruit mass for each plant. Fruit mass is positively correlated

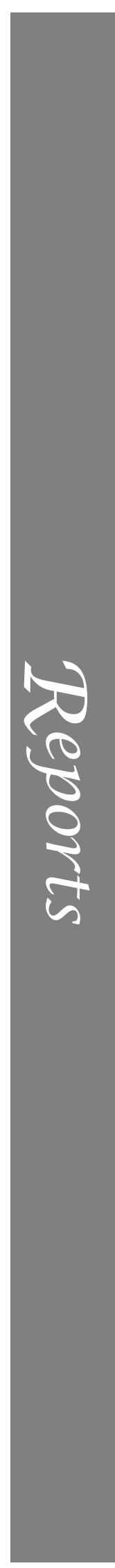



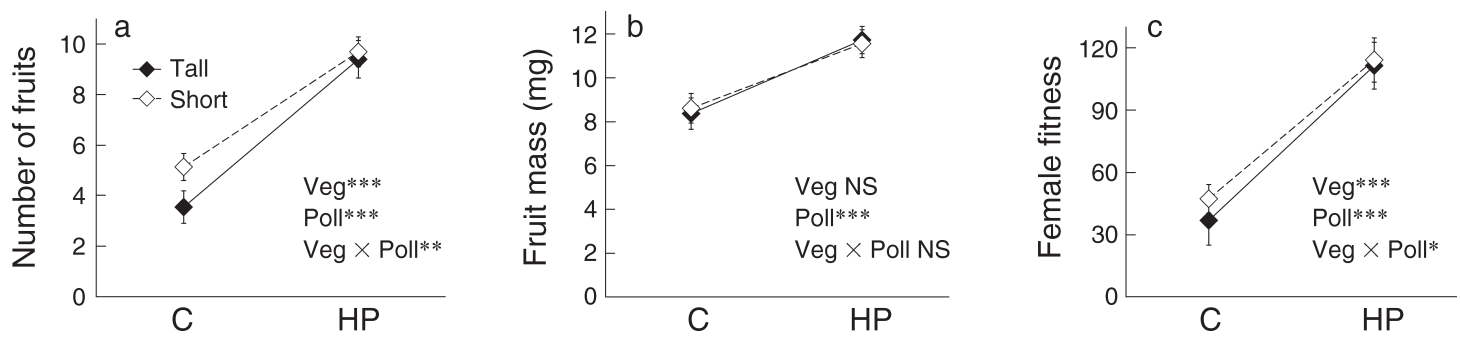

FIG. 1. The effects of pollination regime (poll: open-pollinated control [C] vs. supplemental hand pollination [HP]) and vegetation height (veg: tall vs. short) on (a) number of fruits, (b) fruit mass, and (c) female fitness (number of fruits $\times$ mean fruit mass) in the Dactylorhiza lapponica population (mean $\pm 1.96 \mathrm{SE}$ ). Statistical significance of treatments in two-way ANOVA are indicated (see Appendix: Table A1 for details).

$* P<0.05 ; * * P<0.01$; *** $P<0.001$; NS, not statistically significant.

with number of seeds with embryos in D. lapponica (Sletvold et al. 2010a). For each plant, we estimated female fitness as the product of number of fruits and mean fruit mass. We quantified pollen limitation as $1-$ (mean female fitness of open-pollinated control plants/mean female fitness of hand-pollinated plants).

Plant height (one-way ANOVA; $F_{3,449}=0.27, P=$ $0.85)$, number of flowers $\left(F_{3,449}=0.42, P=0.74\right)$, corolla size $\left(F_{3,449}=0.10, P=0.96\right)$, spur length $\left(F_{3,449}\right.$ $=0.40, P=0.76)$ and flowering start $\left(F_{3,449}=0.69, P=\right.$ $0.56)$ did not differ between the four treatment groups.

\section{Statistical analyses}

We used two-way ANOVA to examine the effects of vegetation height (tall vs. short), pollination treatment (open-pollinated control vs. supplemental hand pollination) and their interaction on number of fruits, mean fruit mass and female fitness. In these models, a significant interaction term between vegetation height and pollination treatment demonstrates that the strength of pollen limitation depends on vegetation height. Number of fruits and female fitness were squareroot transformed to improve normality of residuals.

Selection was estimated following Lande and Arnold (1983), using multiple regression analyses with relative female fitness (individual fitness divided by mean fitness) as the response variable and standardized trait values (with a mean of 0 and a variance of 1) as explanatory variables. Fitness was relativized and traits were standardized separately for each treatment. To limit model complexity in analyses of treatment effects, we only included linear selection gradients.

We used ANCOVA to determine whether vegetation height and pollination treatment influenced linear selection gradients. The model included relative fitness as the dependent variable and the five standardized traits (plant height, number of flowers, corolla size, spur length, and start of flowering), vegetation height (tall vs. short), pollination treatment (open-pollinated control vs. hand pollination), and trait $\times$ vegetation height, trait $x$ pollination treatment and trait $\times$ vegetation height $X$ pollination treatment interactions as independent variables. In this model, a significant trait $\times$ pollination treatment interaction indicates pollinator-mediated selection, while a significant three-way interaction term demonstrates that the strength of pollinator-mediated selection depends on vegetation context. Because a statistically significant three-way interaction was detected, we further tested the effect of pollination treatment on selection gradient estimates separately for each vegetation height, and the effect of vegetation height separately for each pollination treatment. For each vegetation treatment, we quantified pollinator-mediated selection by subtracting for each trait the estimated selection gradient for plants receiving supplemental hand pollination $\left(\beta_{\mathrm{HP}}\right)$ from the estimate obtained for open-pollinated controls $\left(\beta_{\mathrm{C}}\right), \Delta \beta_{\mathrm{poll}}=\beta_{\mathrm{C}}-\beta_{\mathrm{HP}}$ (cf. Sletvold and Ågren 2010). Analyses were performed in SAS 9.3 (SAS Institute, Cary, North Carolina, USA).

\section{RESULTS \\ Pollen limitation}

Female fitness of hand-pollinated plants was significantly higher than that of open-pollinated plants in both vegetation treatments, and pollen limitation was stronger in tall vegetation (significant vegetation $\times$ pollination interaction; Fig. 1c; Appendix: Table A1). Pollen limitation (1 - [mean female fitness of open-pollinated plants/mean female fitness of hand-pollinated plants]) was 0.70 in tall vegetation, and 0.62 in short vegetation. Both components of female fitness, fruit production and fruit mass, were pollen limited in both vegetation treatments, and the effect of pollination treatment on fruit production was significantly stronger in tall compared to short vegetation (significant vegetation $\times$ pollination interaction; Fig. 1a and b; Appendix: Table A1). Supplemental hand pollination increased the number of fruits and fruit mass by $183 \%$ and $43 \%$ in tall vegetation, and by $101 \%$ and $38 \%$ in short vegetation, respectively.

\section{Pollinator-mediated selection}

There was significant selection on floral display and spur length in both vegetation treatments, and vegetation height influenced the strength of selection on floral display. In tall (intact) vegetation, there was directional 
selection for taller plants with more flowers and longer spurs (open-pollinated control plants; Fig. 2a). Pollinators contributed significantly to selection on all three traits (significant pollination $\times$ trait interactions in ANCOVA; plant height $F_{1,219}=3.98, P=0.047$; number of flowers $F_{1,219}=3.87, P=0.050$; spur length $\left.F_{1,219}=9.26, P=0.0026\right)$, and accounted for $89 \%$ of the observed selection on plant height, $45 \%$ of the selection on flower production, and all selection on spur length (Fig. 2a, c). In short vegetation, there was directional selection for more flowers and longer spurs, but no significant selection on plant height (open-pollinated control plants; Fig. 2b). The strength of selection on plant height was significantly reduced compared to tall vegetation (significant vegetation $\times$ plant height interaction in ANCOVA including open-pollinated plants; $\left.F_{1,221}=5.51, \quad P=0.020\right)$. Pollinators contributed significantly to selection on number of flowers and spur length in short vegetation (significant pollination $\times$ trait interactions in ANCOVA; number of flowers $F_{1,210}=$ $3.99, P=0.047$, spur length $F_{1,210}=21.7, P<0.0001$ ), and accounted for $32 \%$ and $100 \%$ of the observed selection, respectively (Fig. 2b,c). The strength of pollinator-mediated selection on flower production and spur length was reduced by $52 \%$ and $25 \%$, compared to estimates from intact tall vegetation (Fig. 2c). The strength of pollinator-mediated selection differed significantly between the two vegetation treatments for plant height (significant vegetation $\times$ pollination $\times$ plant height interaction in ANCOVA; $F_{1,432}=5.63, P=$ $0.018)$, but not for flower production $\left(F_{1,432}=0.82, P=\right.$ $0.37)$ or spur length $\left(F_{1,432}=0.46, P=0.50\right)$. Vegetation height did not significantly influence any selection gradient estimate for hand-pollinated plants (ANCOVA conducted on hand-pollinated plants; all vegetation $X$ trait interactions $P>0.25$ ).

\section{Discussion}

The importance of visual floral traits for pollinator attraction should depend on vegetation context, and the present study demonstrates that vegetation height markedly influences the strength of pollinator-mediated selection on floral display in the deceptive orchid Dactylorhiza lapponica. Experimental reduction of the height of the surrounding vegetation to a level corresponding to that in patches of low vegetation removed all selection on plant height, and reduced the strength of pollinator-mediated selection on number of flowers by $52 \%$. The results show that the importance of pollinators as selective agents on floral traits can be affected strongly by vegetation context.

Vegetation context can influence pollinator-mediated selection by affecting the importance of floral display for pollination success, but also by affecting the overall rate of pollinator visitation and pollen limitation. As expected, the strength of pollinator-mediated selection on spur length tended to be less strongly affected by vegetation context than the strength of selection on
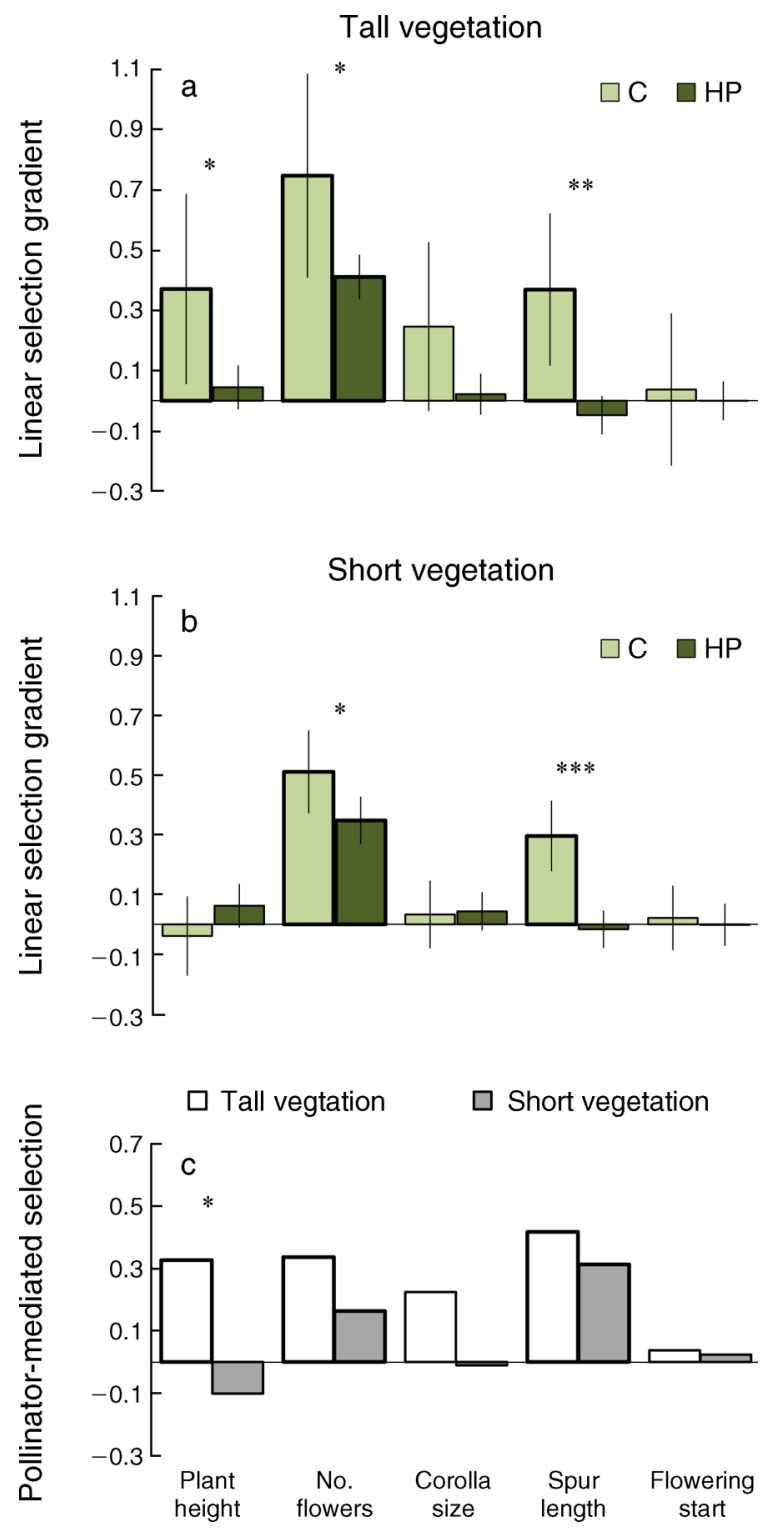

FIG. 2. Phenotypic linear selection gradients $( \pm 1.96 \mathrm{SE})$ and pollinator-mediated selection $\left(\Delta \beta_{\text {poll }}\right)$ on plant height, number of flowers, corolla size, spur length, and start of flowering in the Tågdalen population of Dactylorhiza lapponica. Selection gradients obtained for open-pollinated control plants (C) and plants receiving supplemental hand pollination (HP) in (a) tall and (b) short vegetation, and (c) estimates of the magnitude and direction of pollinator-mediated selection are given. In panels (a) and (b), bars drawn with a bold line indicate significant gradients at the $P<0.05$ level. Asterisks above bars indicate traits for which selection gradients differed between pollination treatments [panels (a) and (b)] and for which pollinator-mediated selection differed between vegetation treatments [panel (c)].

$$
* P<0.05 ; * * P<0.01 ; * * * P<0.001 \text {. }
$$

display traits. Spur length affects the mechanical fit between flower and pollinator (Nilsson 1988, Johnson and Steiner 1997, Boberg and Agren 2009, Sletvold and Ågren 2011a), and vegetation height should have no 

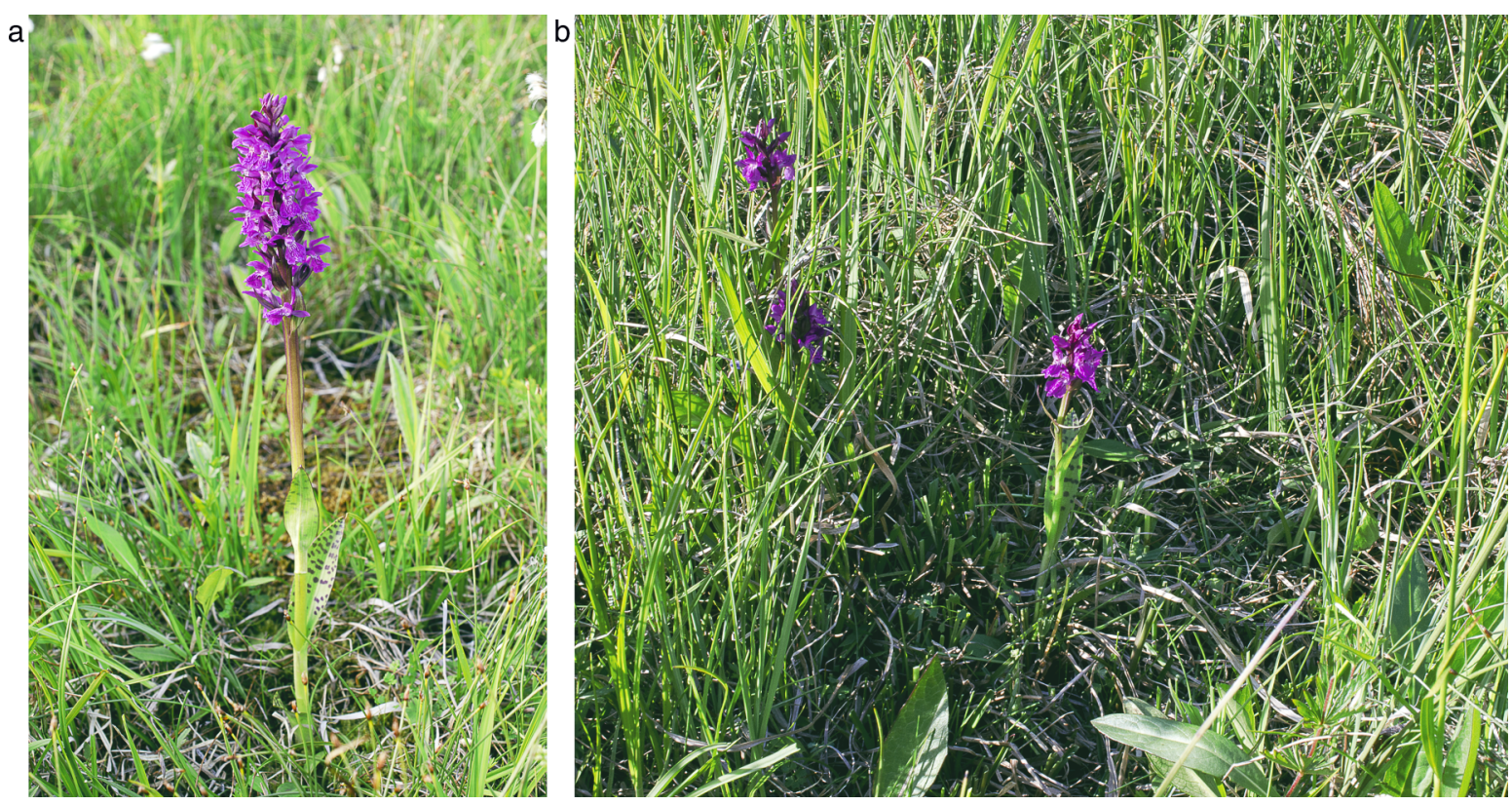

Plate 1. Flowering Dactylorhiza lapponica in (a) short vegetation and (b) tall, dense vegetation at the study site at Tågdalen, central Norway. Vegetation height has been experimentally reduced around the central individual in panel (b). Photo credit: J. M. Grindeland.

direct effect on this relationship. The observed $25 \%$ reduction in pollinator-mediated selection on spur length in short compared to tall vegetation can instead probably be explained by a higher rate of pollinator visitation and weaker pollen limitation in short vegetation. The strength of pollinator-mediated selection through female fitness should decrease with decreasing pollen limitation (Ashman and Morgan 2004), and the experimental reduction in vegetation height reduced the degree of pollen limitation by $11 \%$. In short vegetation, mean female fitness was $25 \%$ higher and the variance in relative fitness was $77 \%$ lower compared to tall vegetation, which should have reduced the opportunity for selection on all traits (cf. Endler 1986). The results are consistent with the hypothesis that vegetation height should influence selection on visual display particularly strongly, but that it may also affect the strength of pollinator-mediated selection more generally because of effects on pollen limitation and the opportunity for selection.

Pollinator-mediated selection on number of flowers was less strongly affected by vegetation context than was pollinator-mediated selection on plant height. There may be at least a couple of reasons why number of flowers is more important than plant height for pollination success in short vegetation. First, many flowers may signal a larger reward to naïve flower visitors. Second, if scent is involved in pollinator attraction, the quantity of scent emitted is likely to be related to the number of open flowers. Dactylorhiza lapponica is not known to produce any scent, but experiments are required to determine conclusively the relative importance of olfactory and visual traits for pollination success in this system.

This study demonstrated experimentally that the strength of selection on floral display in D. lapponica depends on vegetation height, and that differences in selection between short and tall vegetation can be attributed largely to reduced pollinator-mediated selection in the former treatment. There is substantial among-population variation in the pollinator-mediated proportion of selection on floral display in the orchids D. lapponica (N. Sletvold and J. Ågren, unpublished data) and Gymnadenia conopsea, (Sletvold and Ågren 2010, Sletvold et al. 2012; N. Sletvold and J. Ågren, unpublished data), and the present results suggest that variation in vegetation height may contribute to this variation. Moreover, small-scale variation in vegetation height and density is not uncommon within $D$. lapponica populations, suggesting that the strength of selection may vary also within populations. Spatial variation in selection on floral traits has been associated with numerous abiotic and biotic factors (reviewed in Harder and Johnson 2009), and several studies indicate that selection is affected by community context. In the presence of Castilleja linariaefolia, selection on floral traits in Ipomopsis aggregata was shaped by competition for pollination (Caruso 2000). Selection on plant height in Cypripedium acaule varied with the proximity of ericaceous shrubs (O'Connell and Johnston 1998), and selection on flowering phenology in the herb Сатрапиlastrum americanum was contingent on shaded areas in 
the population (Kilkenny and Galloway 2008). Amongpopulation variation in selection on inflorescence height in Primula veris was linked to variation in canopy cover via effects on seed predation (Kolb and Ehrlén 2010). Finally, in one of the few previous studies to manipulate two ecological factors simultaneously, Moeller and Geber (2005) showed that traits promoting reproductive assurance in Clarkia xantiana were favored in small populations isolated from congeners, but not in large populations or when congeners were present. To summarize, both experimental and correlative approaches suggest that spatial variation in vegetation context may often be associated with differences in the strength of selection on floral traits.

Patterns of selection on floral traits may differ between sex functions in hermaphroditic plants (Hodgins and Barrett 2008). We did not quantify effects of vegetation context on selection via male fitness in $D$. lapponica, but earlier results suggest that pollen deposition and pollen removal are closely correlated (Sletvold and Ågren 2011; N. Sletvold, unpublished data). It is thus likely that selection estimates based on pollen removal would parallel those via female function, and that the strength of selection also via male fitness is reduced in short vegetation.

With the experimental protocol employed, it is not possible to distinguish effects of vegetation height from those of reduced density of co-occurring, insect-pollinated plants in the immediate vicinity of focal individuals. The flowering of $D$. lapponica overlaps that of the rewarding Bartsia alpina L. and Pedicularis palustris L., which occur at the study site at rather low densities, and with which $D$. lapponica shares pollinators. Because $D$. lapponica is a food-deceptive orchid, removal of rewardproducing plants can be expected to increase rather than decrease the level of pollen limitation (cf. Johnson et al. 2003). The observed reduction in pollen limitation in short vegetation compared to tall vegetation thus suggests that the effects of reduced vegetation height per se dominated over any reduced facilitation mediated by closely located rewarding plants.

Vegetation removal could lead to increased resource availability through a reduction in interspecific competition (Leger and Rice 2003). In the perennial herb Primula farinosa, simulated grazing of surrounding vegetation increased seed output mainly through increased resource availability, rather than through effects on pollen limitation (Ågren et al. 2006). In contrast, cutting of the surrounding vegetation did not increase seed output of D. lapponica plants receiving supplemental hand pollination. This suggests that vegetation removal had minor effects on resource availability, or that female fitness was not resource limited, at least not in the year of study. Fruit set of supplementally handpollinated plants has been high during three years in the study population (94-98\%; N. Sletvold, unpublished data), indicating that prevailing resource levels allow maximal fruit set. However, reproductive costs have been documented in several orchids (Snow and Whigham 1989, Primack and Stacy 1998, Sletvold and Ågren 2011b), suggesting that the strong increase in reproduction may trade off against future survival and reproduction in $D$. lapponica, potentially influencing selection on floral traits.

Understanding adaptive evolution requires insight in the phenotypic traits subject to selection and the ecological factors that cause selection, something that remains a challenge in most systems (MacColl 2011). The present study demonstrates that crossed manipulations of environmental factors can provide a quantitative understanding of how the importance of a given selective agent varies with environmental context, and we suggest that such experiments will be particularly useful for improved insights in the causes of natural selection.

\section{ACKNOWLEDGMenTS}

Financial support from the Swedish Research Council Formas (N. Sletvold), and the Swedish Research Council (J. Ågren) is acknowledged.

\section{Literature Cited}

Ågren, J., C. Fortunel, and J. Ehrlén. 2006. Selection on floral display in insect-pollinated Primula farinosa: effects of vegetation height and litter accumulation. Oecologia 150: 225-232.

Ashman, T.-L., and M. T. Morgan. 2004. Explaining phenotypic selection on plant attractive characters: male function, gender balance or ecological context? Proceedings of the Royal Society B 271:553-559.

Bartowska, M. P., and M. O. Johnston. 2012. Pollinators cause stronger selection than herbivores on floral traits in Lobelia cardinalis (Lobeliaceae). New Phytologist 193:1039-1048.

Boberg, E., and J. Ågren. 2009. Despite their apparent integration, spur length but not perianth size affects reproductive success in the moth-pollinated orchid Platanthera bifolia. Functional Ecology 23:1022-1028.

Caruso, C. M. 2000. Competition for pollination influences selection on floral traits of Ipomopsis aggregata. Evolution 54:1546-1557.

Caruso, C. M., S. L. Scott, J. C. Wray, and C. A. Walsh. 2010. Pollinators, herbivores, and the maintenance of flower color variation: a case study with Lobelia siphilitica. International Journal of Plant Sciences 171:1020-1028.

Ehrlén, J., S. Käck, and J. Ågren. 2002. Pollen limitation, seed predation and scape length in Primula farinosa. Oikos 97:4551.

Endler, J. A. 1986. Natural selection in the wild. Princeton University Press, Princeton, New Jersey, USA.

Fishman, L., and J. H. Willis. 2008. Pollen limitation and natural selection on floral characters in the yellow monkeyflower, Mimulus guttatus. New Phytologist 177:802-810.

Galen, C. 1996. Rates of floral evolution: adaptation to bumblebee pollination in an alpine wildflower, Polemonium viscosum. Evolution 50:120-125.

Harder, L. D., and S. D. Johnson. 2009. Darwin's beautiful contrivances: evolutionary and functional evidence for floral adaptation. New Phytologist 183:530-545.

Hodgins, K. A., and S. C. H. Barrett. 2008. Natural selection on floral traits through male and female function in wild populations of the heterostylous daffodil Narcissus triandrus. Evolution 62:1751-1763.

Johnson, S. D., C. I. Peter, L. A. Nilsson, and J. Ågren. 2003. Pollination success in a deceptive orchid is enhanced by cooccurring rewarding magnet plants. Ecology 84:2919-2927.

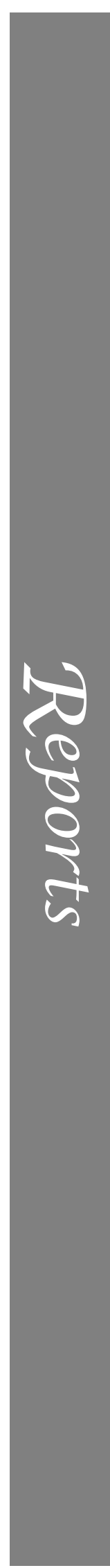


Johnson, S. D., and K. E. Steiner. 1997. Long-tongued fly pollination and evolution of floral spur length in the Disa draconis complex (Orchidaceae). Evolution 51:45-53.

Kilkenny, F. F., and L. F. Galloway. 2008. Reproductive success in varying light environments: direct and indirect effects of light on plants and pollinators. Oecologia 155:247255.

Kingsolver, J. G., S. E. Diamond, A. M. Siepielski, and S. M. Carlson. 2012. Synthetic analyses of phenotypic selection in natural populations: lessons, limitations and future directions. Evolutionary Ecology 26:1101-1118.

Kingsolver, J. G., H. E. Hoekstra, J. M. Hoekstra, D. Berrigan, S. N. Vignieri, C. E. Hill, A. Hoang, P. Gibert, and P. Beerli. 2001. The strength of phenotypic selection in natural populations. American Naturalist 157:245-261.

Kolb, A., and J. Ehrlén. 2010. Environmental context drives seed predator-mediated selection on a floral display trait. Evolutionary Ecology 24:433-445.

Lande, R., and S. J. Arnold. 1983. The measurement of selection on correlated characters. Evolution 37:1210-1226.

Leger, E. A., and K. J. Rice. 2003. Invasive California poppies (Eschscholzia californica Cham.) grow larger than native individuals under reduced competition. Ecology Letters 6: 257-264.

Leimu, R., K. Syrjänen, J. Ehrlén, and K. Lehtilä. 2002. Predispersal seed predation in Primula veris: among-population variation in damage intensity and selection on flower number. Oecologia 133:510-516.

MacColl, A. D. C. 2011. The ecological causes of evolution. Trends in Ecology and Evolution 26:514-522.

Moeller, D. A., and M. A. Geber. 2005. Ecological context of the evolution of self-pollination in Clarkia xantiana: population size, plant communities, and reproductive assurance. Evolution 59:786-799.

Nilsson, A. N. 1988. The evolution of flowers with deep corolla tubes. Nature 334:147-149.

O'Connell, L. M., and M. O. Johnston. 1998. Male and female pollination success in a deceptive orchid, a selection study. Ecology 79:1246-1260.
Parachnowitsch, A. L., and A. Kessler. 2010. Pollinators exert natural selection on flower size and floral display in Penstemon digitalis. New Phytologist 188:393-402.

Primack, R. B., and E. Stacy. 1998. Costs of reproduction in the pink lady's slipper orchid (Cypripedium acaule, Orchidaceae): an eleven-year experimental study in three populations. American Journal of Botany 85:1672-1679.

Sandring, S., and J. Ågren. 2009. Pollinator-mediated selection on floral display and flowering time in the perennial herb Arabidopsis lyrata. Evolution 63:1292-1300.

Siepielski, A. M., J. D. DiBattista, and S. M. Carlson. 2009. It's about time: the temporal dynamics of phenotypic selection in the wild. Ecology Letters 12:1261-1276.

Sletvold, N., and J. Ågren. 2010. Pollinator-mediated selection on floral display and spur length in the orchid Gymnadenia conopsea. International Journal of Plant Sciences 171:9991009.

Sletvold, N., and J. Ågren. 2011a. Nonadditive effects of floral display and spur length on reproductive success in a deceptive orchid. Ecology 92:2167-2174.

Sletvold, N., and J. Ågren. 2011b. Among-population variation in costs of reproduction in the long-lived orchid Gymnadenia conopsea: an experimental study. Oecologia 167:461-468.

Sletvold, N., J. M. Grindeland, and J. Ågren. 2010a. Pollinatormediated selection on floral traits and flowering phenology in the deceptive orchid Dactylorhiza lapponica. New Phytologist 188:385-392.

Sletvold, N., D.-I. Øien, and A. Moen. 2010b. Long-term influence of mowing on population dynamics in the rare orchid Dactylorhiza lapponica: the importance of recruitment and seed production. Biological Conservation 143:747-755.

Sletvold, N., J. Trunschke, C. Wimmergren, and J. Ågren. 2012. Separating selection by diurnal and nocturnal pollinators on floral display and spur length in Gymnadenia conopsea. Ecology 93:1880-1891.

Snow, A. A., and D. F. Whigham. 1989. Costs of flower and fruit production in Tipularia discolor (Orchidaceae). Ecology 70:1286-1293.

Wade, M. J., and S. Kalisz. 1990. The causes of natural selection. Evolution 44:1947-1955.

\section{Supplemental Material}

\section{Appendix}

ANOVA results of the effects of vegetation height, pollination regime, and their interaction on number of fruits, mean fruit mass, and female fitness (Ecological Archives E094-112-A1). 